\title{
Effect of Curcuma zedoaria crude extract against tumor progression and immunomodulation
}

\section{Carvalho FR (1), Vassão RC (2), Nicoletti MA (3), Maria DA (1)}

(1) Laboratory of Biochemistry and Biophysics, Butantan Institute, São Paulo, São Paulo State, Brazil; (2) Laboratory of Cell Biology, Butantan Institute, São Paulo, São Paulo State, Brazil; (3) Department of Pharmacy, University of São Paulo, São Paulo, São Paulo State, Brazil.

ABSTRACT: The aim of the present work was to study the effect of the crude extract of Curcuma zedoaria on peripheral blood cells and tumor progression in C57BI/6J mice injected with B16F10 murine melanoma cells. The intraperitoneal therapy showed a significant increase in total white and red blood cell counts, a decrease in peritoneal cell number and tumor volume reduction, whereas the oral administration revealed a noteworthy augmentation only in total leukocyte count. These results contribute to evaluate the importance of alternative treatments that employ phytotherapic compounds against tumor progression and its possible immunomodulation.

KEY WORDS: melanoma, tumor, hematology, Curcuma zedoaria.

CONFLICTS OF INTEREST: There is no conflict.

\section{CORRESPONDENCE TO:}

DURVANEI AUGUSTO MARIA, Laboratório de Bioquímica e Biofísica, Instituto Butantan, Av. Vital Brasil, 1500, São Paulo, SP, 05.503-900, Brasil. Phone:+55 11 3726 7222, ext. 2364. Email: durvanei@usp.br. 


\section{INTRODUCTION}

Curcuma zedoaria Roscoe (Zingiberaceae family) is a phytotherapic agent traditionally cultivated in Asian countries and largely employed in oriental medicine. According to the traditional Chinese medicine, C. zedoaria rhizomes contain several specific sesquiterpenes that are effective against flatulent colic, debility of the digestive organs, amenorrhea, hepatocirrhosis, cancer, oxidation and human blood aggregation (1-5). Moreover, its rhizome is generally used as stomachic in Japan whereas in Chinese medicine it has been prescribed for the treatment of blood stagnation syndromes and for promoting menstruation (6).

Among the main hepatoprotective sesquiterpenes isolated from the aqueous acetone extract of C. zedoaria rhizome, furanodiene, germacrone, curdione, neocurdione, curcumenol, isocurcumenol, aerugidiol, zedoarondiol, curcumenone and curcumin revealed potent effect on D-galactosamine- (D-Gain) and lipopolysaccharide- (LPS) induced acute liver injury in mice. Action mechanisms for their hepatoprotective activity were elucidated based on the inhibitory effect on D-Gain-induced cytotoxicity in primary cultured rat hepatocytes, LPS-induced nitric oxide (NO) production in cultured mouse peritoneal macrophages, and D-Gain and tumor necrosis factor- $\alpha$ (TNF- $\alpha$ ) induced liver injury in mice (6).

More than 20 sesquiterpenes, curcuminoids, and ethyl p-methoxycinnamate were reported as chemical constituents of $C$. zedoaria $(7,8)$. In a previous study, a crude ethanolic extract of $C$. zedoaria showed inhibitory effect against OVCAR-3 cells (human ovarian cancer) (7). Furthermore, a fraction of $C$. zedoaria ethanolic extract has shown potent antitumoral and enzymatic actions in vitro (7).

In the present study, we evaluated the effects of crude C. zedoaria extract administered either orally and intraperitonially, as well as the impact of extract sesquiterpenes on B16F10 melanoma growth.

\section{MATERIALS AND METHODS}

\section{Fluid Extract Preparation}

One thousand grams of dried root were divided into three portions: $500 \mathrm{~g}, 300 \mathrm{~g}$ and $200 \mathrm{~g}$. The 500-g sample was humidified, saturated with the extraction liquid (ethanol $70^{\circ} \mathrm{GL}$ ) and percolated. The first aliquot of $200 \mathrm{~cm}^{3}$ of percolate was stored until use, and the percolation continued up to $1,500 \mathrm{~cm}^{3}$, which was collected in aliquots of 300 
$\mathrm{cm}^{3}$ each, so that the more concentrated extract was separated from the last weak percolates.

The second amount of dried root $(300 \mathrm{~g})$ was moistened, humidified and saturated with the percolates collected during the previous step. The first volume of $300 \mathrm{~cm}^{3}$ was collected and percolation continued up to $1,000 \mathrm{~cm}^{3}$, which was collected in 200$\mathrm{cm}^{3}$ aliquots. Finally, the third fraction of the root $(200 \mathrm{~g})$ was moistened, humidified and saturated with the remaining percolates and processed similarly to the second sample. Five hundred cubic centimeters of percolate were collected and mixed with the two samples $\left(200\right.$ and $300 \mathrm{~cm}^{3}$ ) previously obtained, thus totalizing $1,000 \mathrm{~cm}^{3}$ of fluid extract.

\section{Animals and Treatment}

Groups of five 1.5-month-old C57BI/6J male mice, weighing between 20 and $25 \mathrm{~g}$, were intraperitoneally injected with or orally received, once a week, different Curcuma zedoaria doses diluted in water. The control group was injected with the same concentrations of the extraction liquid diluted in water. The other groups received two different doses (orally or intraperitoneally) of Curcuma zedoaria, 0.1 and $0.2 \%$, diluted in water.

The animals were weighed weekly and $10 \mu \mathrm{L}$ of blood was collected from the venous retrorbital plexus in the presence of heparin (5,000 UI, Roche). Blood smears from each sample were spread on glass slides, fixed with methanol for five minutes, airdried and stained (1:4) with Giemsa ${ }^{\circledR}$ (Merck, Germany) for differential leukocyte count. Total saline diluted red blood cell suspension and Turk stained (1:10) total leukocytes were counted under a microscope Axiovert 40 MAT® (Zeiss, Germany) with a hemocytometer chamber of the Malassez type.

After three months (oral route treatment) and two months (intraperitoneal treatment), the animals were killed and underwent necropsy, then, peritoneum cells were washed with $2 \mathrm{~mL}$ of iced PBS. The peritoneal exudate was collected and total resident cells were counted on Malassez chambers. The different types of leukocytes were placed on glass slides (Cytospin ${ }^{\circledR}$ Centrifuge, Eppendorf, USA), stained with DifQuick $®$ (Merck, Germany) and, afterward, analyzed and counted under a microscope. The results concerning the effects of different doses of Curcuma zedoaria treatment were compared with the control group, and subjected to a 
statistical analysis (Student's t-test: $p<0.05,0.01>p>0.001$ and $p<0.001$ ). Data were expressed as mean \pm SD for each experimental group.

\section{Treatment of Primary Tumor Growth of B16F10 Cells}

B16F10 murine melanoma cells were obtained from the Ludwig Institute of Cancer, Switzerland. Groups of five C57BI/6J mice were subcutaneously injected with $5 \times 10^{4}$ B16F10 melanoma cells. Subsequently, the animals were treated with Curcuma zedoaria extract as aforementioned. The tumor growth was observed weekly and its volume was calculated using the following formula: (length) ${ }^{2} \times$ (width) $x(\pi / 6)$. The efficacy of the treatment was calculated as the ratio of tumor size in treated animals to the tumor size in control animals.

The statistical analysis was performed using the Student's t-test $(p<0.05,0.01>p>$ 0.001 and $p<0.001)$.

\section{RESULTS}

Our results indicate that the oral treatment of normal mice with the extract does not induce significant alterations on red blood cells number; whereas in the intraperitoneal administration there was an increase on red blood cell count after 15 and 60 days of treatment (Figure $1-\mathrm{A}, \mathrm{B}$ and $\mathrm{C}$ ).

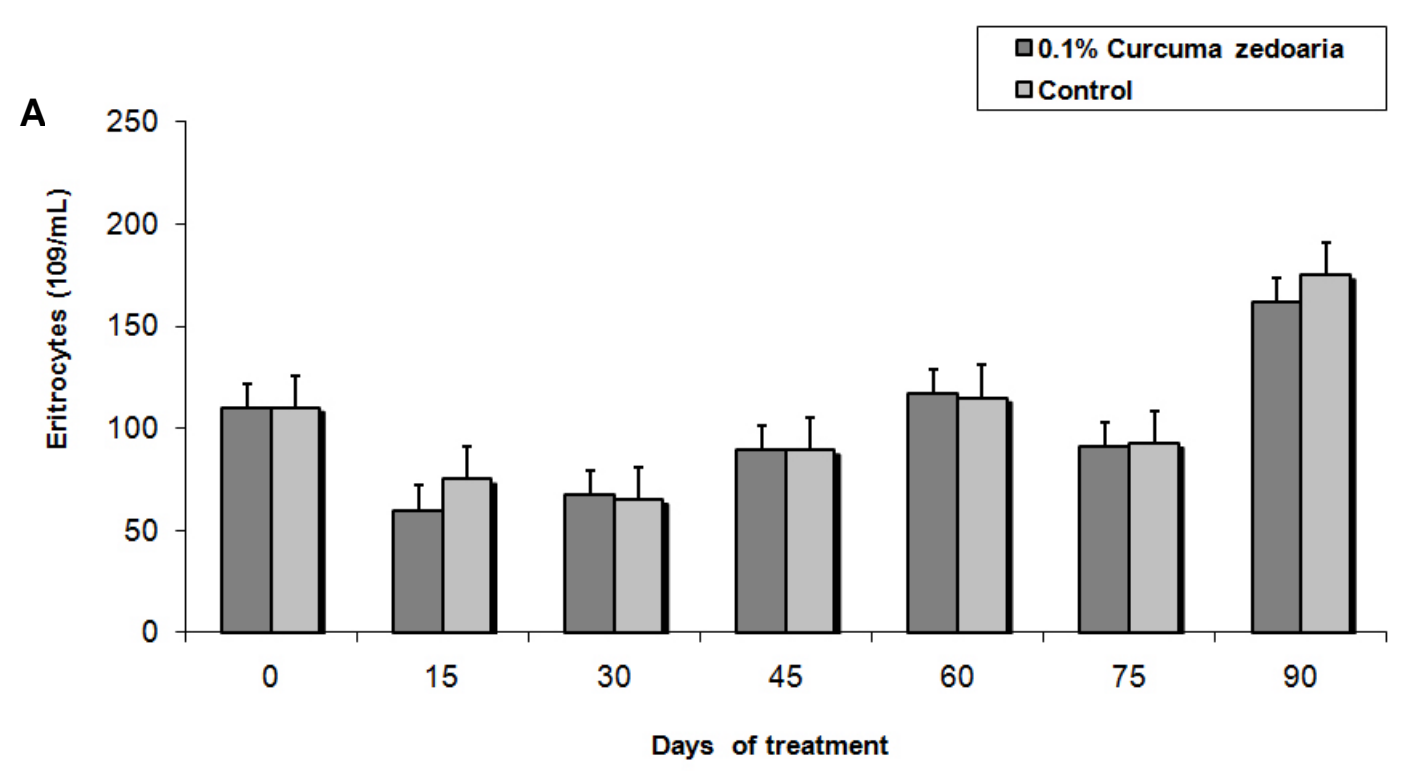



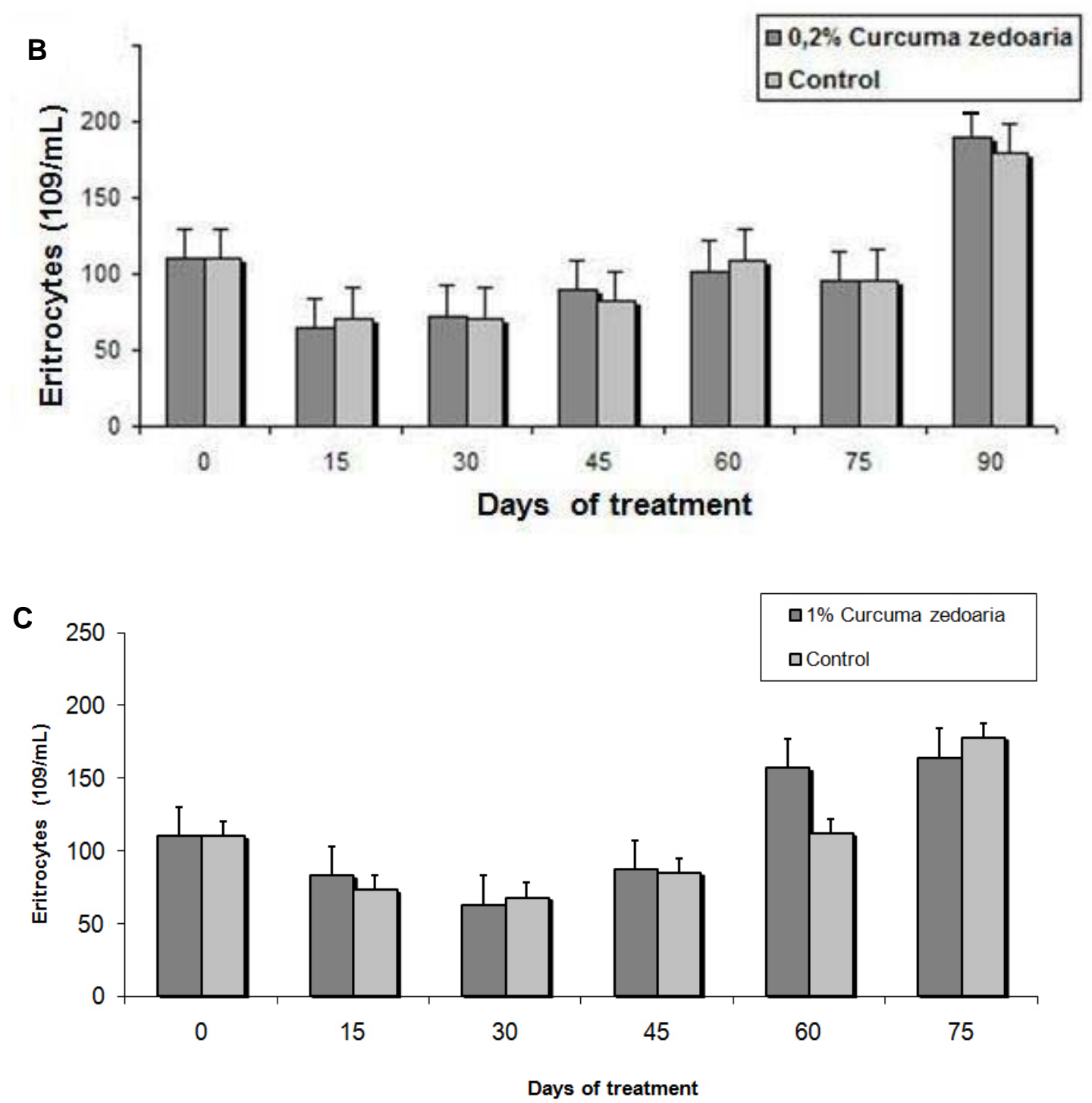

Figure 1. Analysis of total erythrocytes in the blood of C57BL/6J mice treated with (A) $0.1 \%$; (B) $0.2 \%$ or (C) $1 \%$ Curcuma zedoaria crude extract.

Data are expressed as mean $\pm \mathrm{SD}$.

There was no weight lost among the different treated groups when they were compared with control groups (data not shown).

The intraperitoneally treated group showed an increase in total leukocyte count 15 , 30 and 45 days after treatment (Figure $2-C$ ), while the oral administration led to an augmentation in total leukocyte number 30 and 45 days after treatment at both concentrations (Figure $2-\mathrm{A}$ and $\mathrm{B}$ ). 

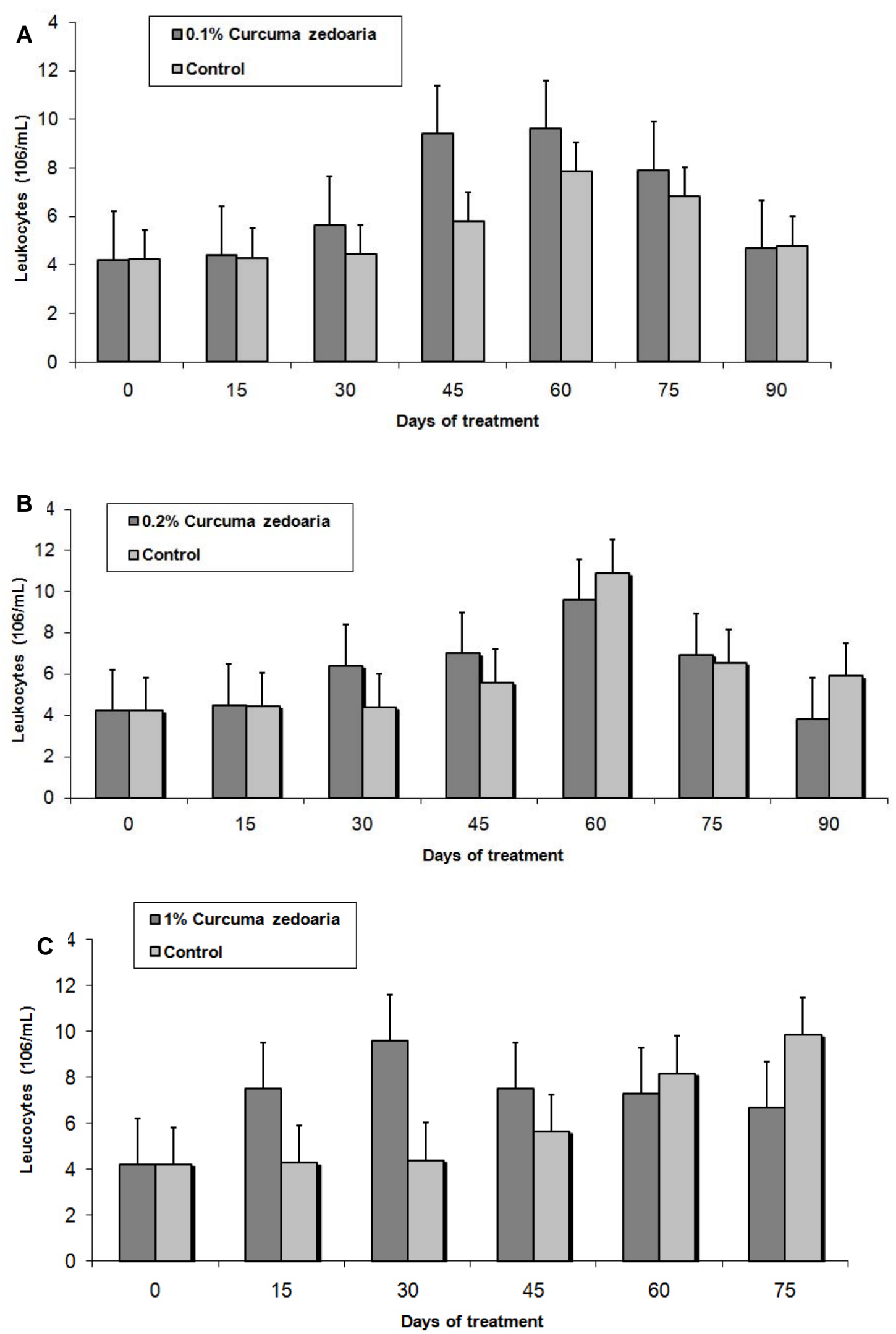

Figure 2. Analysis of total leukocytes in the blood of C57BL/6J mice treated with (A) $0.1 \%$; (B) $0.2 \%$ or (C) $1 \%$ Curcuma zedoaria crude extract.

Data are expressed as mean \pm SD. 
The differential analysis of orally treated mice showed an increase in the lymphocyte count 30 and 45 days after treatment with $0.1 \%$ Curcuma zedoaria extract; whereas regarding the $0.2 \%$ extract, an elevation was noticed 15 and 30 days after the administration. Similarly, $0.1 \%$ Curcuma zedoaria extract augmented the number of neutrophils 15 days after treatment, reached a peak within 60 days and, then, returned to normal levels in 90 days. The same behavior was observed in animals treated with the $0.2 \%$ extract (Figure $3-\mathrm{A}$ and $\mathrm{B}$ ).

The differential analysis of the intraperitoneal administration revealed an increase in lymphocyte number after 15 and 30 days, a monocyte increase after 15, 30 and 45 days and an elevation of neutrophils 15 days after treatment. The number of monocytes dropped 60 days after treatment (Figure $3-\mathrm{C}$ ).
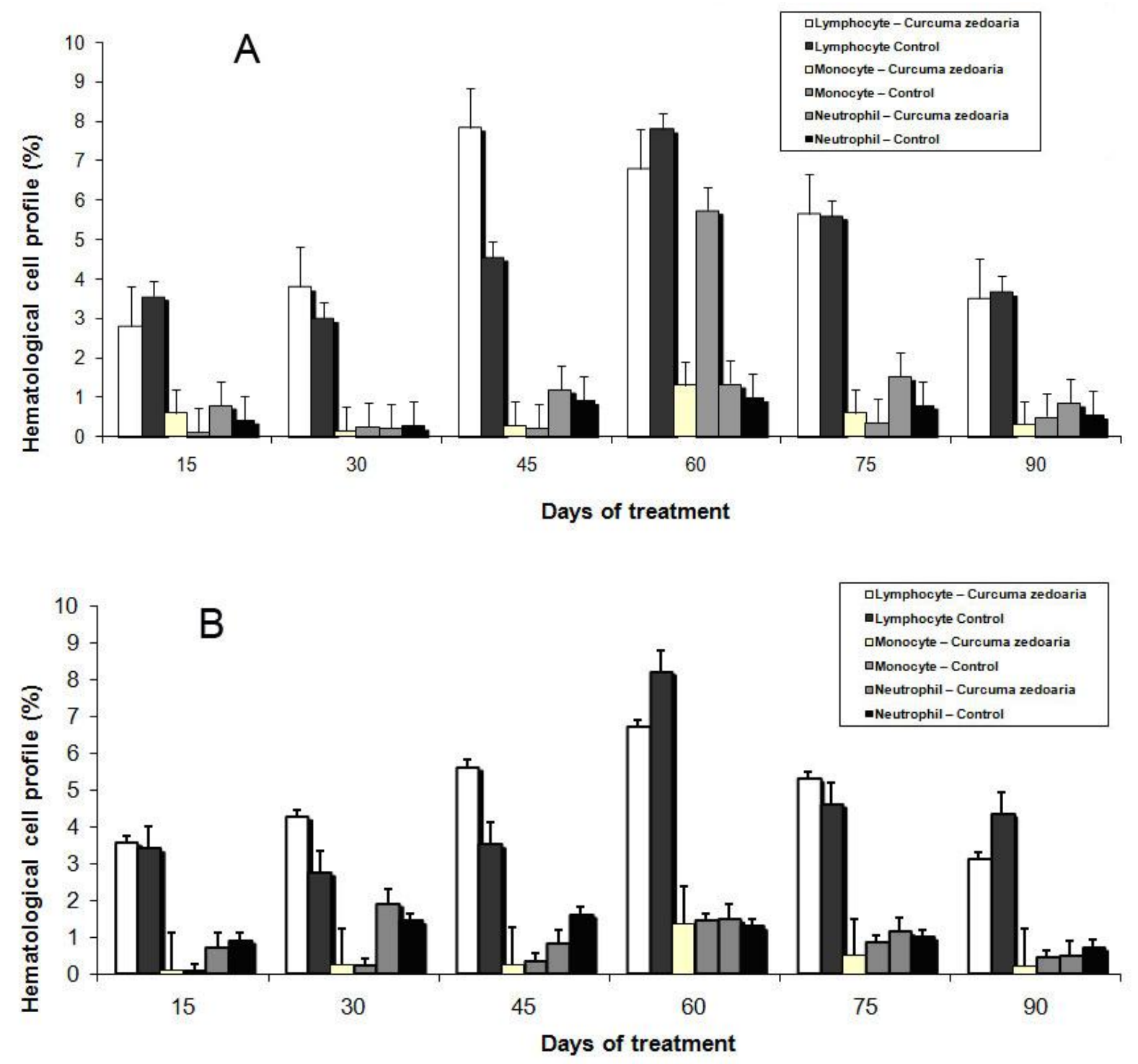


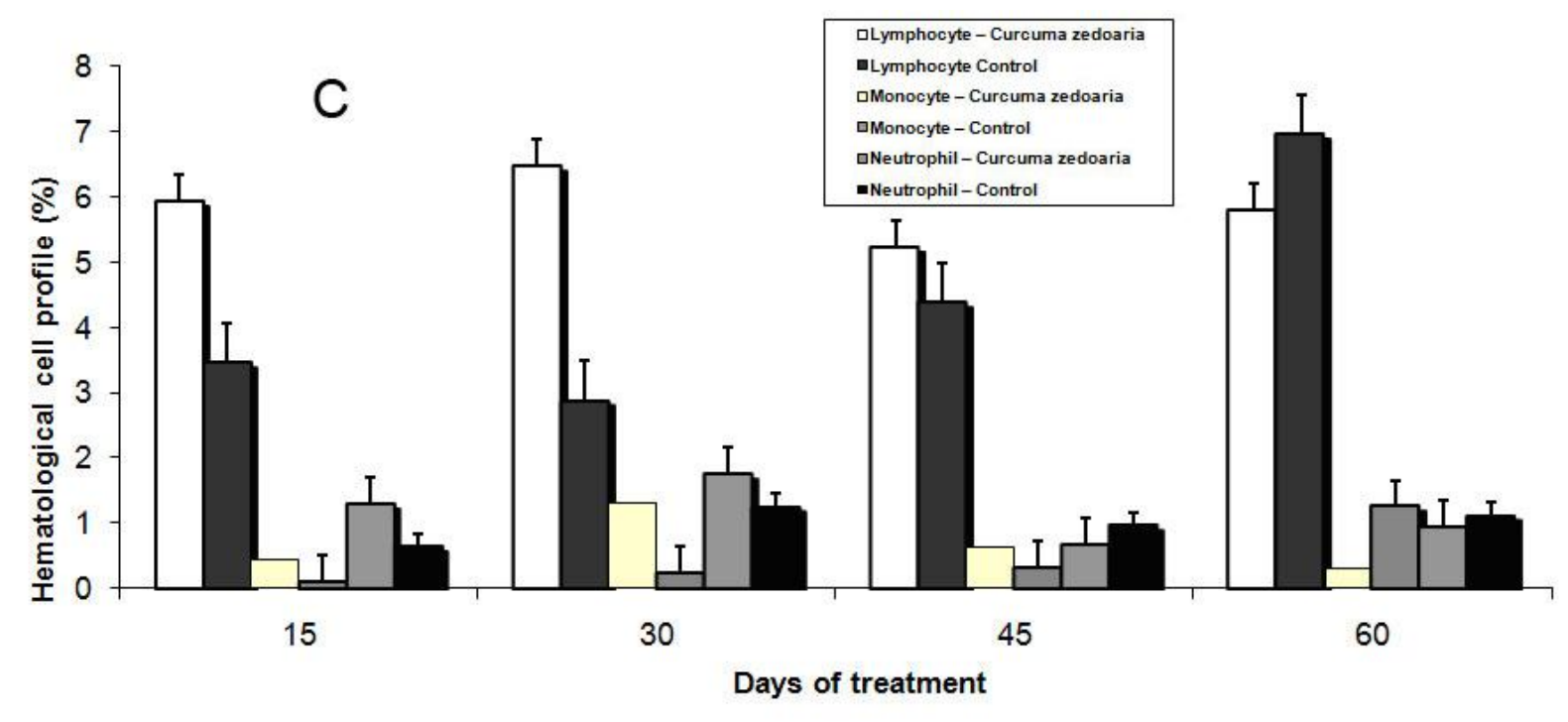

Figure 3. Differential analysis of leukocytes in the blood of C57BL/6J mice treated with (A) $0.1 \%$; (B) $0.2 \%$ or (C) $1 \%$ Curcuma zedoaria crude extract.

Data are expressed as mean \pm SD.

There was no alteration in the number of peritoneal cells concerning orally treated animals; however, mice intraperitoneally treated had a significant decrease in peritoneal cell count (Figure 4) The differential analysis of peritoneal cells showed a reduced number of macrophages in the animal groups that received orally $0.1 \% C$. zedoaria extract treated and intraperitoneally $1 \%$ extract (Figure 5).

After the B16F10 melanoma cell inoculation, animals were daily observed. Data in Figure 6 (A) display a reduction in the tumor volume during the first couple of weeks of intraperitoneal treatment. There was no alteration in the tumor area (Figure $6-\mathrm{B}$ ). After the crude extract treatment, animals were killed and tumors and lymphatic nodes were analyzed. Photomicrographs of dorsal tumors and draining nodes showed infiltrated tumor cells in the lymphatic system with mast cells granulations and also a large number of mast cells in primary tumors (Figure 7). The photomicrographs of dorsal tumors are shown in Figure 8. 


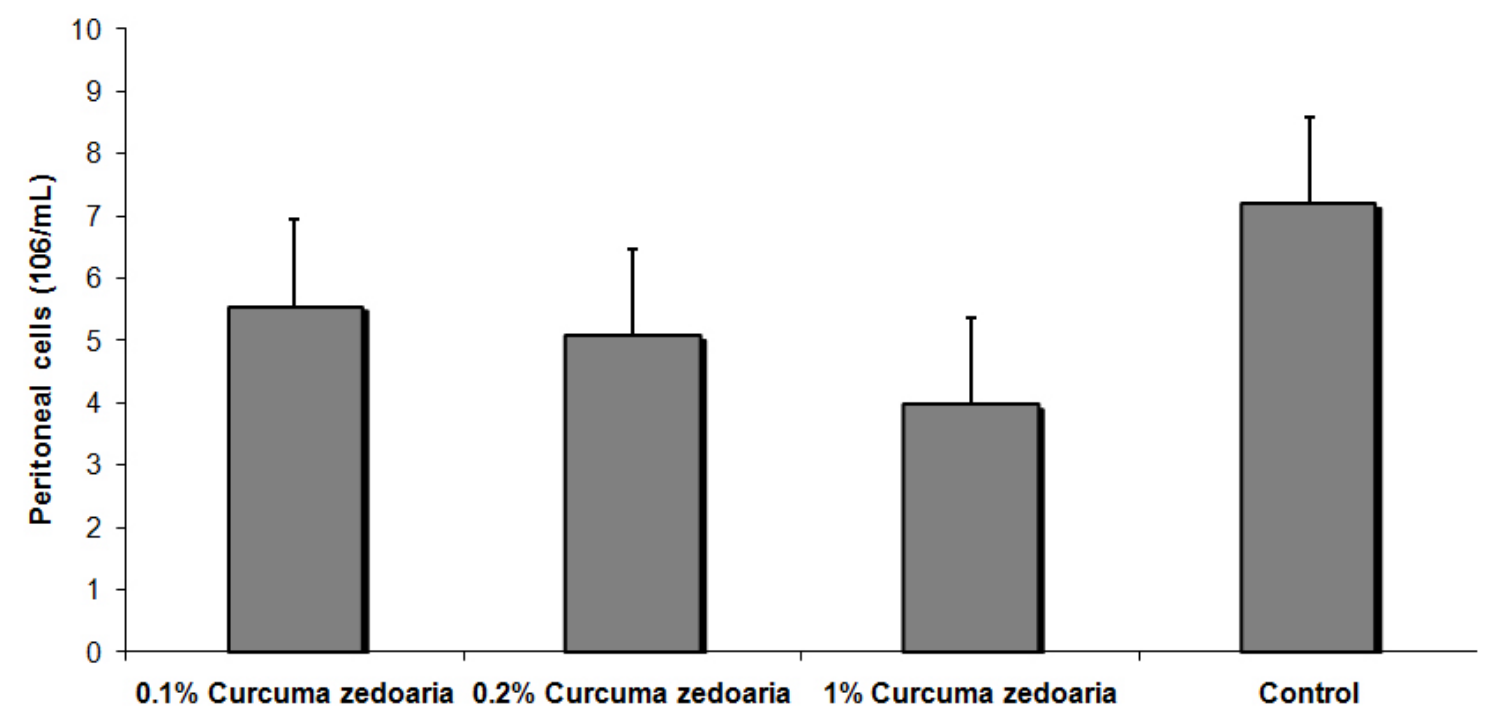

Figure 4. Cell migration to the peritoneal cavity. C57BL/6J mice were treated with $0.1,0.2$ and $1 \%$ Curcuma zedoaria crude extract.

Data are expressed as mean \pm SD.

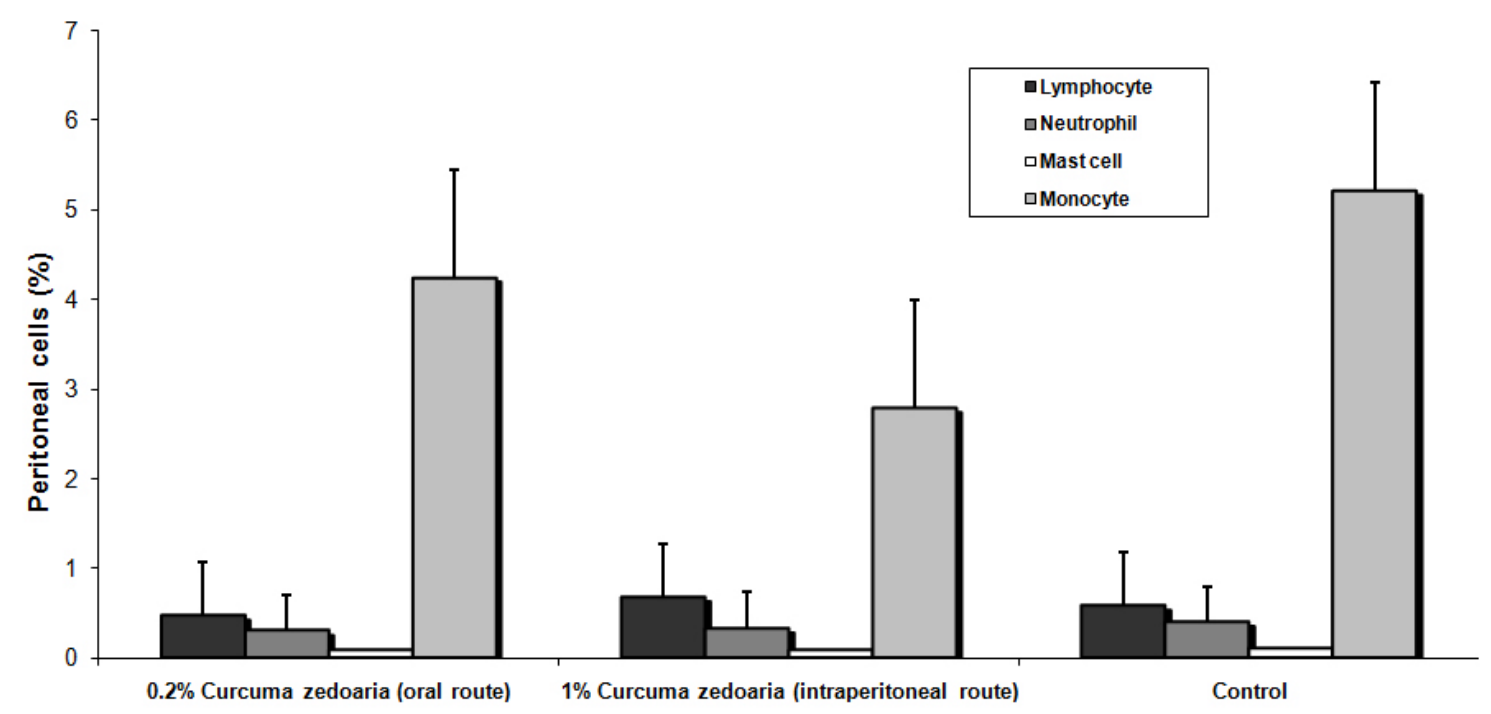

Figure 5. Differential cell migration to the peritoneal cavity. C57BL/6J mice were treated with 0.2 or $1 \%$ Curcuma zedoaria crude extract.

Data are expressed as mean $\pm S D$. 

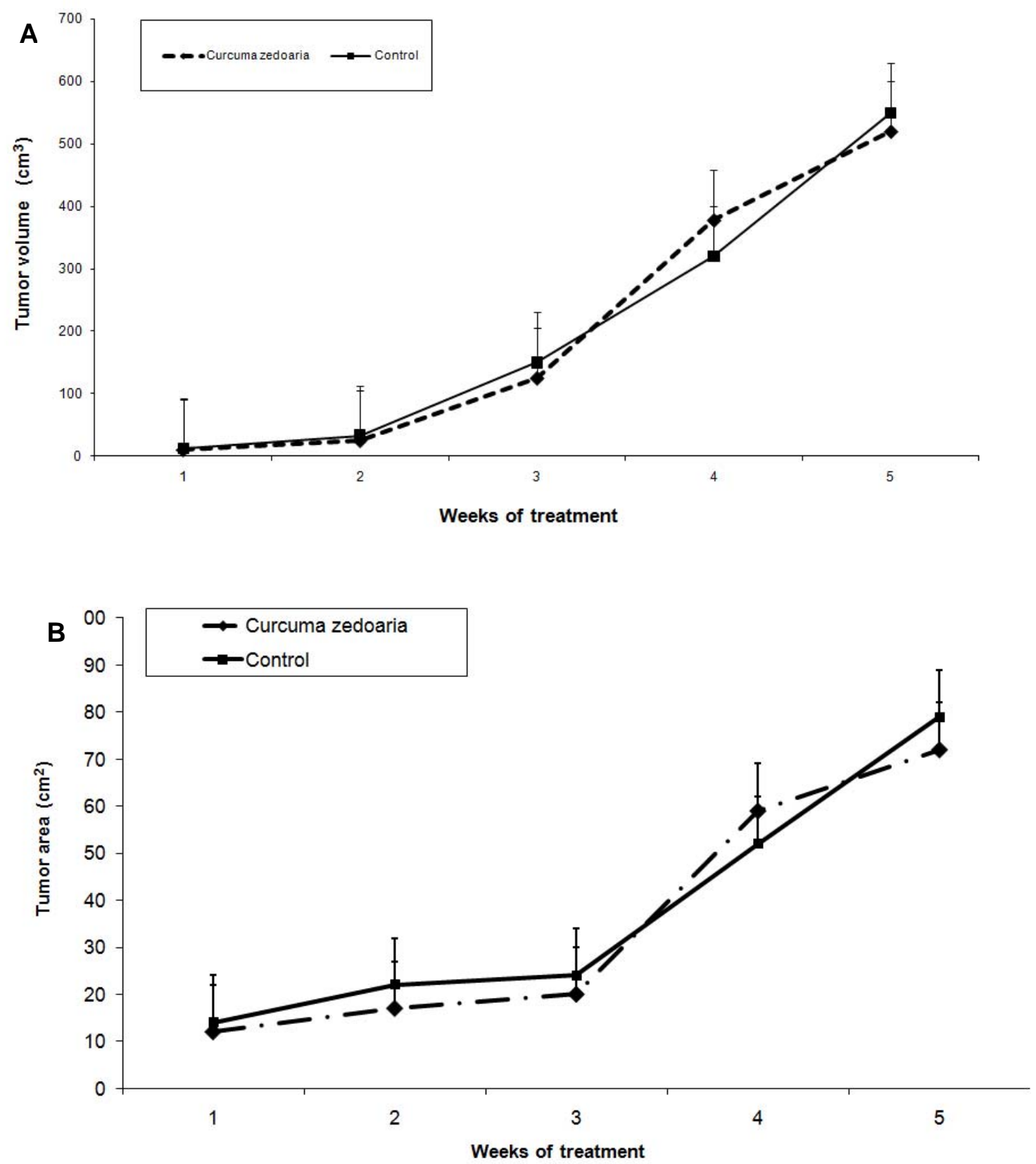

Figure 6. (A) Analysis of dorsal B16F10 tumor growth in C57BL/6J mice treated with $0.2 \%$ Curcuma zedoaria. (B) Analysis of dorsal B16F10 tumor area in C57BL/6J mice treated with $0.2 \%$ Curcuma zedoaria.

Data are expressed as mean $\pm S D$. 
Carvalho FR et al. Effect of Curcuma zedoaria crude extract against tumor progression and immunomodulation. J Venom Anim Toxins incl Trop Dis. 2010;16(2):334

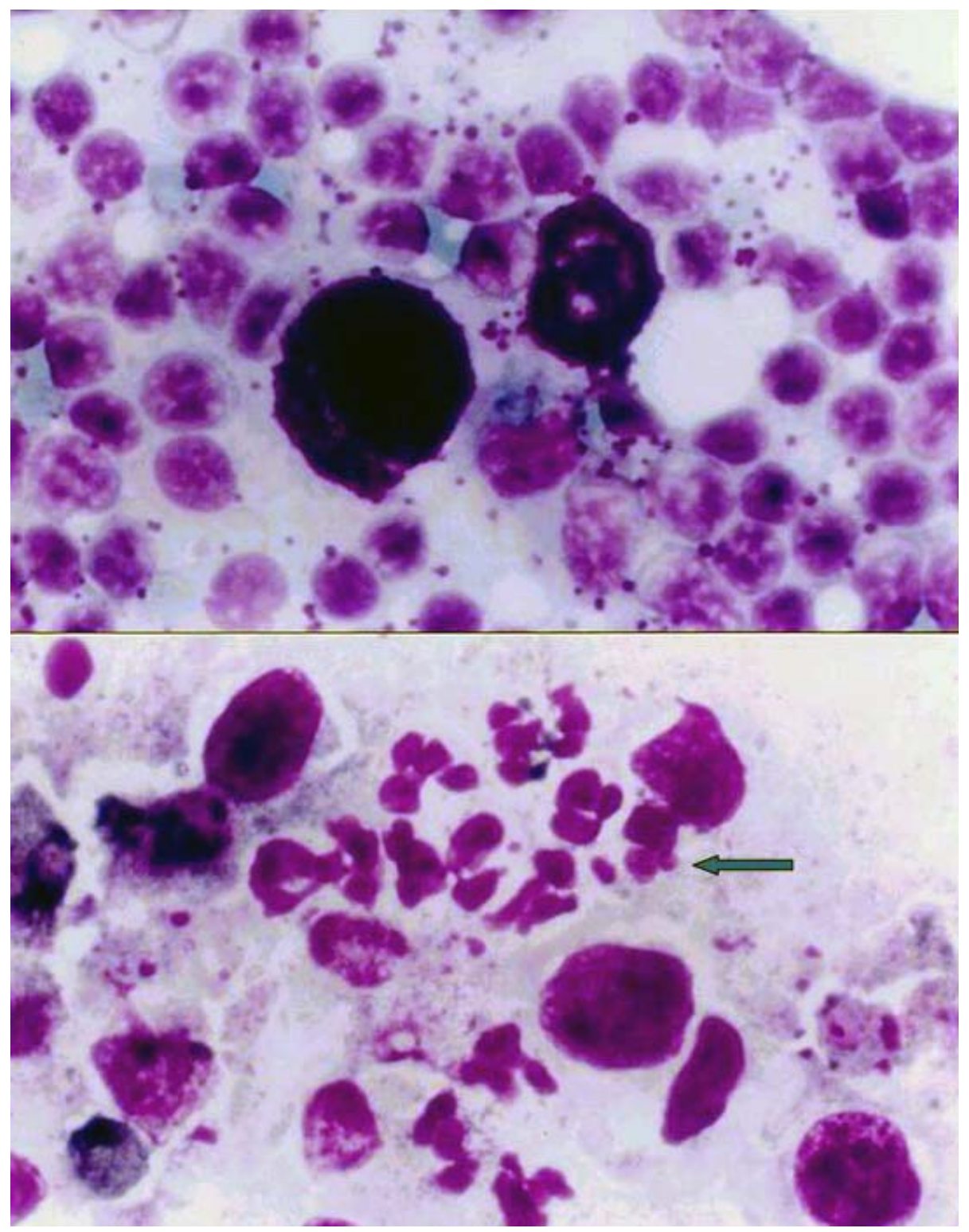

Figure 7. Light micrograph of infiltrated tumor cells in lymph nodes after dorsal implantation of B16F10 melanoma cells followed by Curcuma zedoaria crude extract injection. 

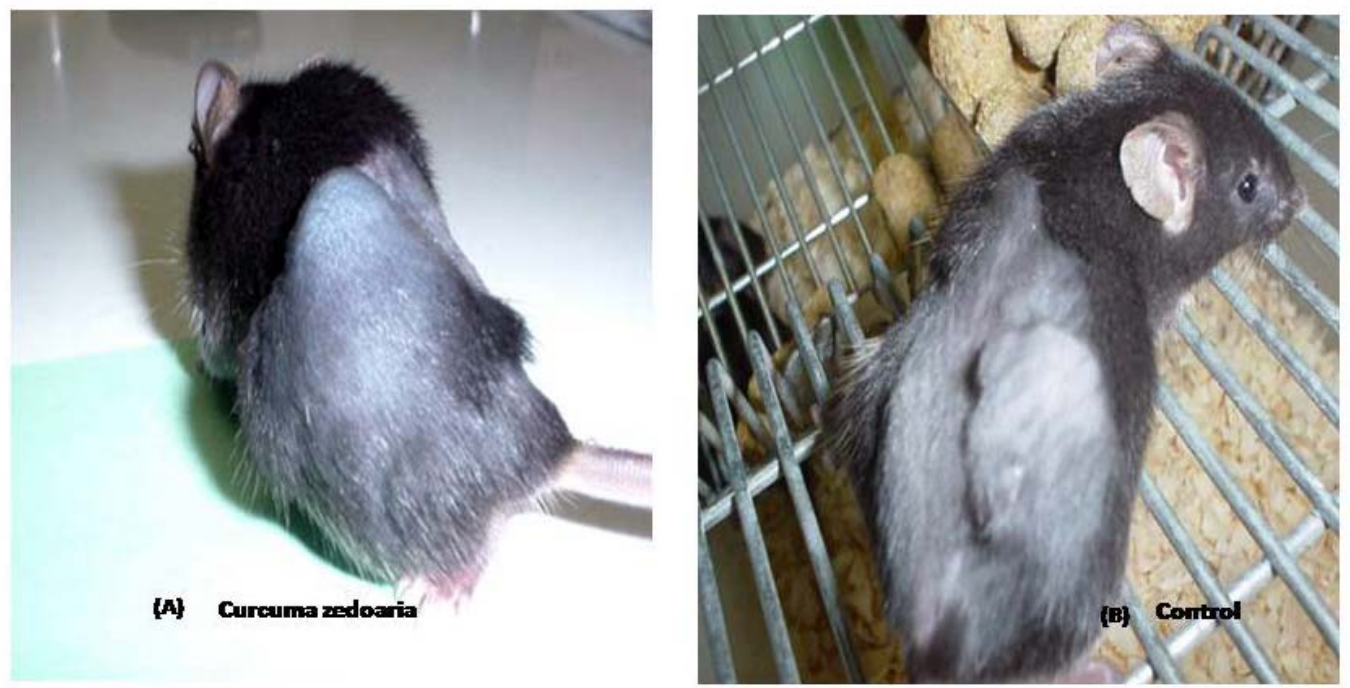

Figure 8. Effects of Curcuma zedoaria on subcutaneous B16F10 tumor growth. B16F10 melanoma cells ( $5 \times 10^{4}$ /mouse) were subcutaneously injected in the dorsal region of $\mathrm{C} 57 \mathrm{BL} / 6 \mathrm{~J}$ mice, in the absence (controls) or presence of $C$. zedoaria extract $(0.2 \%)$. The tumor volumes were monitored by periodic caliper measurement. (A) Group treated with C. zedoaria and (B) control group.

\section{DISCUSSION}

To study the regulation of B16F10 melanoma tumour growth by a phytotherapic agent in vitro and in vivo, firstly, antitumor and inflammatory responses to Curcuma zedoaria extract treatment were assessed. Recently, considerable attention has been focused on identifying naturally occurring chemopreventive substances capable of inhibiting, retarding, or reversing the tumoral growth. Numerous phenolic substances present in fruits and vegetables or in medicinal plants have been found to retain potential cancer chemopreventive activities. For most known chemopreventive phytochemicals, however, their protective effects are based solely on results of animal tests.

Dehydrocurdione, a major sesquiterpene, has shown an analgesic effect in mice by decreasing the number of writhes induced by acetic acid and inhibiting carrageenaninduced paw edema. The curcuma extract has also proven to promote an important decrease in free radicals production. Moreover, the anti-inflammatory potency of dehydrocurdione may be related to its antioxidant effect (1). 
Several works on epidemiology and animal model studies demonstrated that natural compounds, which possess antioxidant or anti-inflammatory properties, could inhibit carcinogenesis (9-12).

In vitro studies have shown that a fraction from the ethanolic extract of $C$. zedoaria has a powerful antitumoral action and promotes macrophage activation, causing an increase in phagositosis and in oxidative burst in vivo. In addition, it was noticed that high molecular weight compounds have strong macrophage-stimulating activity and low molecular weight compounds (curcumin, curzerenone and zedoarone) present antifungal activity (2).

Curcumin (diferuloylmethane) is a yellow odourless pigment isolated from the rhizome of tumerics (Curcuma longa Linn, Zingiberaceae and Curcuma zedoaria Roscoe). This substance possesses anti-inflammatory and antioxidant properties, as well as inhibits lipopolysaccharide and interferon-induced production of nitric oxide or nitrite in macrophages (13-21). Curcumin is one of the most extensively investigated and well-defined chemopreventive phytochemicals and has been shown to protect against skin, oral, intestinal and colon carcinogenesis and also to suppress angiogenesis and metastasis in a variety of animal tumour models (22-24). It also inhibits the proliferation of cancer cells by arresting them in various phases of the cell cycle and by inducing apoptosis $(22,24)$.

Dehydrocurdione and lactones are the major sesquiterpenes in zedoary. The antiinflammatory effect of dehydrocurdione is likely to be different from that of nonstereoidal anti-inflammatory drugs, while sesquiterpene lactones have been shown to inhibit activation of a transcriptional factor NFkB, which, in turn, regulates different gene transcription related to cellular inflammatory response (25).

Modern medicine attributes most cases of cancer to changes in DNA that reduce or eliminate the normal controls over cellular growth, maturation and programmed cell death. Herb prescriptions that used to be given to cancer patients as the sole therapy primarily contained plants that were said to remove or counteract toxins, eliminate or diminish accumulations, restore normal circulation and promote the functions of the internal organs. In an effort to remove these accumulations (cell masses, such as a tumor), an herb that was often utilized is curcuma (26).

Curcuma zedoaria contains volatile oils and when its extract is injected into mice that have tumors, the tumors shrink. It is believed that the enhanced fibrinolysis and other processes stimulated by volatile oils allow immune system cells to enter the tumor 
and consume or destroy the tumor cells. In Chinese medicine, C. zedoaria is employed to treat cervical cancer by injecting its oil into the tumor mass. Moreover, it is believed that this type of herbs have low toxicity (26).

The ethanolic extract of $C$. Zedoaria contains three identified active curcuminoids, namely curcumin, demethoxycurcumin and bisdemethoxycurcumin, which were found to possess inhibitory activity against tumor growth and to be cytotoxic to murine sarcoma, transformed NIH 3T3 fibroblast cells, human colon cancer cell lines (HCT-15 and HT-29), human embryonic kidney cell line (HEK293), human hepatocellular carcinoma and Hep-2 cells (7, 10, 11). Furthermore, Kim et al. (3) found that the polysaccharide fraction from $C$. zedoaria effectively inhibited the growth of implanted sarcoma 180 in mice.

One method of cancer therapy currently under investigation is the inhibition of tumor angiogenesis. The blood vessels of surrounding normal tissue are eliminated or displaced by the tumor, thus weakening the surrounding tissue and making it more susceptible to replacement by tumors mass. A fibrin coating that prevents immune cells of the blood stream from entering and destroying the tumor often surrounds tumors. Blood-activating herbs are usually prescribed in Chinese medicine to cancer patients in order to promote positive effects against cancer. A group of herbs classified as blood-activating, including C. zedoaria, are used to counter all those problems, direct cancer-inhibiting actions on tumor cells and promote immune system attack against cancer cells (26).

The maintenance of homeostasis in normal mammalian tissue reflects a critical balance between cell proliferation and cell death via apoptosis. Selected chemopreventive vitamins or phytochemicals have the propensity for suppressing or retarding the growth of cancer cells (27-29). Moreover, some phenolic substances derived from Zingiberaceae plants have potent anti-inflammatory activity and induce apoptosis in human cancer cell lines $(11,30,31)$. Additionally, curcumin from $C$. zedoaria also protects against chemically induced liver damage in experimental animals $(32,33)$. Similarly, another study observed that topical application of curcumin onto mouse dorsal skin significantly inhibited epidermal cyclooxygenase and lipooxygenase (34). Seo et al. (35) reported a suppressive effect of zedoary rhizome on pulmonary metastasis of B16 melanoma cells.

The majority (60\%) of the identified and approved antineoplastic drugs in the 1990 s are originated from natural products. Natural sources are abundant and offer the best 
possibilities to find substances of interest in oncology. Some chemotherapy drugs currently used against diverse tumors are derived from natural plants, such as alkaloids that have basic chemical properties and usually contain at least one nitrogen atom in a heterocyclic ring obtained from Vinca rosea, etoposide from Podophyllum peltatum and taxol isolated from Taxus brevifolia tree. There are other substances that originate from microorganisms, such as L-asparaginase from Escherichia coli and cytarabine from Cryptotethya crypta (36).

Natural products probably represent the most accessible and abundant source of substances of yet unknown structures, some presenting antitumoral activity and new specific mechanisms of action, eventually not described until the present date.

\section{REFERENCES}

1.Yoshioka T, Fujii E, Endo M, Wada K, Tokunaga $Y$, Shiba N, et al. Antiinflamatory potency of dehydrocurdione, a zedoary-derived sesquiterpene. Inflamm Res. 1998;47(12):476-81.

2. Jang MK, Sohn DH, Ryu JH. A curcuminoid and sesquiterpenes as inhibitors of macrophage TNF- $\alpha$ release from Curcuma zedoaria. Planta Med. 2001;67(6): 550-2.

3. Kim KI, Kim JW, Hong BS, Shin DH, Cho HY, Kim HK, et al. Antitumor, genotoxicity and anticlastogenic activities of polysaccharide from Curcuma zedoaria. Mol Cells. 2000;10(4):392-8.

4. Kim KI, Shin KS, Jun WJ, Hong BS, Shin DH, Cho HY, et al. Effects of polysaccharides from rhizomes of Curcuma zedoaria on macrophage functions. Biosci Biotechnol Biochem. 2001;65(11):2369-77.

5. Lee H, Lin JY. Antimutagenic activity of extracts from anticancer drugs in Chinese medicine. Mutat Res. 1988;204(2):229-34.

6. Matsuda H, Ninomiya K, Morikawa T, Yoshikawa M. Inhibitory effect and action mechanism of sesquiterpenes from Zedoariae rhizome on Dgalactosamine/lipopolysaccharide-induced liver injury. Bioorg Med Chem Lett. 1998;8(4):339-44.

7. Syu WJ, Shen CC, Don MJ, Ou JC, Lee GH, Sun CM. Cytotoxicity of curcuminoids and some novel compounds from Curcuma zedoaria. J Nat Prod. 1998;61(12):15314. 
8. Anuchapreeda S, Leechanachai $P$, Smith MM, Ambudkar SV, Limtrakul P. Modulation of P-glycoprotein expression and function by curcumin in multidrugresistant human KB cells. Biochem Pharmacol. 2002;64(4):573-82.

9. Rajakrishnan V, Shiney SJ, Sudhakaran PR, Menon VP. Effect of curcumin on ethanol-induced stress on mononuclear cells. Phytother Res. 2002;16(2):171-3.

10. Hanif R, Qiao L, Shiff SJ, Rigas B. Curcumin, a natural plant phenolic food additive, inhibits cell proliferation and induces cell cycle changes in colon adenocarcinoma cell lines by a prostaglandin-independent pathway. J Lab Clin Med. 1997;130(6):576-84.

11. Jiang MC, Yang-Yen HF, Yen JJ, Lin JK. Curcumin induces apoptosis in immortalized NIH 3T3 and malignant cancer cell lines. Nutr Cancer. 1996;26(1):11120.

12. Limtrakul P, Anuchapreeda S, Lipigorngoson S, Dunn FW. Inhibition of carcinogen induced c-Ha-ras and c-fos proto-oncogenes expression by dietary curcumin. BMC Cancer. 2001;1(1):1.

13. Amom HP, Wahl MA. Pharmacology of Curcuma longa. Planta Med. 1991; 57(1):1-7.

14. Sharma OP. Antioxidant activity of curcumin and related compounds. Biochem Pharmacol. 1976;25(15):1811-2.

15. Rao TS, Basu N, Siddiqui HH. Anti-inflammatory activity of curcumin analogues. Indian J Med Res 1982;75(1):574-8.

16. Mukhopadhyay A, Basu N, Ghatak N, Gujral PK. Anti-inflammatory and irritant activities of curcumin analogues in rats. Agents Actions. 1982;12(4):508-15.

17. Toda S, Miyase T, Arichi H, Tanizawa H, Takino Y. Natural antioxidants. III. Antioxidative components isolated from rhizome of Curcuma longa L. Chem Pharm Bull (Tokyo). 1985;33(4):1725-8.

18. Srivastava R, Srimal RC. Modification of certain inflammation-induced biochemical changes by curcumin. Indian J Med Res. 1985;81(1):215-23.

19. Lin JK, Shih Ca. Inhibitory effect of curcumin on xanthine dehydrogenase/oxidase induced by phorbol-12-myristate-13-acetate in NIH3T3 cells. Carcinogenesis. 1994;15(8):1717-21.

20. Sugiyama $Y$, Kawakishi $S$, Osawa $T$. Involvement of the $\beta$-diketone moiety in the antioxidative mechanism of tetrahydrocurcumin. Biochem Pharmacol. 1996;52(4):519-25. 
21. Brouet I, Ohshima H. Curcumin, an anti-tumor promoter and anti-inflammatory agent, inhibits induction of nitric oxide synthase in activated macrophages. Biochem Biophys Res Commun. 1995;206(2):533-40.

22. Surh YJ, Chun KS. Cancer chemopreventive effects of curcumin. Adv Exp Med Biol. 2007;595(1):149-72.

23. Patel BB, Majumdar AP. Synergistic role of curcumin with current therapeutics in colorectal cancer: minireview. Nutr Cancer. 2009;61(6):842-6.

24. Ravindran J, Prasad S, Aggarwal BB. Curcumin and cancer cells: how many ways can curry kill tumor cells selectively? AAPS J. 2009;11(3):495-510.

25. Lyss G, Schmidt TJ, Merfort I, Pahl HL. Helenalin, an anti-inflammatory sesquiterpene lactone from Arnica, selectively inhibits transcription factor NFkappaB. Biol Chem. 1997;378(9):951-61.

26. Zhu YP, Woerdenbag HJ. Traditional Chinese herbal medicine. Pharm World Sci. 1995;17(4):103-12.

27. Lotan R. Retinoids and apoptosis: implications for cancer chemoprevention and therapy. J Natl Cancer Inst. 1995;87(22):1655-7.

28. Yu R, Mandlekar S, Harvey KJ, Ucker DS, Kong AN. Chemopreventive isothiocyanates induce apoptosis and caspase-3-like protease activity. Cancer Res. 1998;58(3):402-8.

29. Sundaram SG, Milner JA. Diallyl disulfide induces apoptosis of human colon tumour cells. Carcinogenesis. 1996;17(4):669-73.

30. Lee E, Park KK, Lee JM, Chun KS, Kang JY, Lee SS, et al. Suppression of mouse skin tumour promotion and induction of apoptosis in HL-60 cells by Apinia oxyphylla Miquel (Zingiberaceae). Carcinogenesis. 1998;19(8):1377-81.

31. Kuo ML, Huang TS, Lin JK. Curcumin, an anti-oxidant and anti-tumor promoter, induces apoptosis in human leukemia cells. Biochim Biophys Acta. 1996;1317(2):95100.

32. Kiso $\mathrm{Y}$, Suzuki $\mathrm{Y}$, Watanabe $\mathrm{N}$, Oshima $\mathrm{Y}$, Hikino H. Antihepatotoxic principles of curcuma longa Rhizomes 1. Planta Med. 1983;49(11):185-7.

33. Soni KB, Rajan A, Kuttan R. Reversal of aflatoxin induced liver damage by turmeric and curcumin. Cancer Lett. 1992;66(2):115-21.

34. Huang MT, Lysz T, Ferraro T, Abidi TF, Laskin JD, Conney AH. Inhibitory effects of curcumin on in vitro lipooxygenase and cyclooxygenase activities in mouse epidermis. Cancer Res. 1991;51(3):813-9. 
Carvalho FR et al. Effect of Curcuma zedoaria crude extract against tumor progression and immunomodulation. J Venom Anim Toxins incl Trop Dis. 2010;16(2):341

35. Seo WG, Hwang JC, Kang SK, Jin UH, Suh SJ, Moon SK, et al. Suppressive effect of Zedoariae rhizome on pulmonary metastasis of B16 melanoma cells. J Ethnopharmacol. 2005;101(1-3):249-57.

36. Beach M. China opens drug market by revising pharmaceutical law. Lancet. 2001;357(9260):942. 